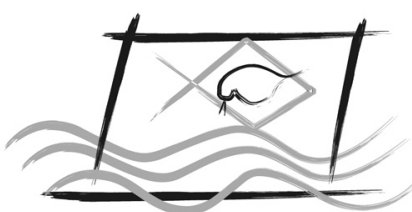

ECOTOX - BRASIL

\title{
Danos citogenotóxicos em ecossistema aquático submetido a esgotamento sanitário urbano
}

\author{
I.T.D. CABAnElas ${ }^{1} \&$ L.M.A. Moreira ${ }^{2}$ \\ ${ }^{1}$ Laboratório de Genetica Humana e Mutagênese \\ ${ }^{2}$ Departamento de Biologia Geral, Instituto de Biologia, Campus Universitário de Ondina, Universidade Federal da Bahia (UFBA). \\ Salvador - BA, Brasil
}

(Received December 22, 2009; Accept May 28, 2011)

\begin{abstract}
Resumo
O intenso crescimento populacional acompanhado de tratamentos inadequados de resíduos, tem resultado na destruição de ambientes dulciaquícolas em ecossistemas urbanos. O rio Sapato constitui o principal efluente na divisa dos municípios de Lauro de Freitas e Salvador, no estado da Bahia. Não obstante o crescente fluxo de despejo doméstico ao qual está submetido, inexistem dados ecotoxicológicos sobre este recurso hídrico. O objetivo do presente estudo foi avaliar a citogenotoxidade da água do rio Sapato, em pontos de proximidade de esgotamento sanitário, utilizando o bioensaio de micronúcleos $(\mathrm{MN})$ e alterações nucleares (AN) em tilápia nilótica (Oreochromis niloticus). A análise foi feita em região sob emissão de esgoto sanitário e nascente, nas estações seca (novembro e dezembro/2006) e chuvosa (março e abril/2007), sendo observadas 3000 células por animal $(\mathrm{n}=10)$. Os resultados foram analisados com o teste Kruskal Wallis e indicaram diferenças sazonais e uma freqüência maior de $\mathrm{MN}$ e $\mathrm{AN}$ no ponto submetido a esgotamento sanitário, em comparação aos valores do sítio referência. Conclui-se que as áreas impactadas já apresentam danos genocitotóxicos.
\end{abstract}

Palavras-chave: anormalidades nucleares, esgotamento urbano, genotoxicidade, micronúcleo

\section{Cytogenotoxic damages in an ecosystem impacted with urban sewage}

\begin{abstract}
The intense population growth accompanied by inadequate treatments of waste has resulted in destruction of freshwater ecosystems in urban environments. The Sapato River is an important effluent on the border of the municipalities of Lauro de Freitas and Salvador in Bahia state (Brazil). Despite the increasing flow of domestic waste, there are no toxicological data on this water resource. The aim of this study was to evaluate the cytogenotoxicity of the Sapato river water, in the vicinity of sewage, using the bioassay of micronuclei (MN) and nuclear abnormalities (NA) in tilapia nilotica (Oreochromis niloticus). The analysis was made in the region under sanitary sewage and in the springs, both in dry (November and December/2006) and rainy seasons (March and April/2007), with analysis of 3000 cells per animal $(n=10)$. The analysis followed literature established criteria, applying the Kruskal Wallis test. Results obtained indicated seasonal differences and a higher frequency of $\mathrm{MN}$ and NA at the point subjected to sanitary sewage comparated to the values of reference site. We conclude that the impacted areas already show cytogenetic damage.
\end{abstract}

Keywords: genotoxicity, micronuclei, nuclear abnormalities, waste water. 


\section{INTRODUÇÃO}

Nos últimos anos tem aumentado a presença de compostos xenobióticos nos ecossistemas aquáticos, principalmente em decorrência de ação antropogênica. Chama-se atenção para a importância de tais ecossistemas, uma vez que, de toda a água doce do mundo (3\%), apenas $0.01 \%$ deste percentual está disponível sob a forma de rios e lagos, as principais fontes de abastecimento humano (CETESB, 2006).

Desse modo, o biomonitoramento torna-se de fundamental importância para a preservação das fontes ainda em bom estado, na medição do grau de deterioração das impactadas e em estudos sobre a possível recuperação. Para isso são utilizados bioindicadores, espécies que são capazes de gerar respostas a alterações no ambiente. Respostas biológicas produzidas no material genético da célula, em organismos expostos a alterações ambientais são denominadas biomarcas de citogenotoxicidade, que podem ser observadas no nível individual (variáveis biométricas) ou nos níveis fisiológicos, celulares, sub-celulares e moleculares.

Dentre as biomarcas mais utilizadas para avaliações de respostas ambientais/laboratoriais, está o ensaio do micronúcleo (MN), que foi inicialmente proposto como um teste para detecção de agentes carcinogênicos em células de medula óssea de camundongo (Cabrioti, 2005). Posteriormente vários protocolos foram desenvolvidos aplicando o teste em outros organismos e em linhagens celulares diversas, tais como humanos, roedores, anfíbios, peixes, moluscos bivalves, ouriços e plantas (Venier et al., 1997; Fenech, 2000; Ribeiro, 2003; Rodrigues et al., 2005; Carvalho, 2005). O bioensaio de MN teve rápida aceitação como bioindicador da qualidade dos ecossistemas aquáticos, especialmente com o uso de peixes, devido principalmente à padronização da técnica, rápidos resultados e fácil adaptação para estudos in situ.

$\mathrm{O}$ teste do micronúcleo em tilápia nilótica (O. niloticus), peixe onívoro e detritívoro, de larga distribuição, apresenta utilização crescente nestas investigações (Çavas \& Ergenegozuka, 2003; Matsumoto, et al., 2005; Souza \& Fontanetti, 2006). Micronúcleos são cromossomos ou fragmentos destes formados durante a divisão celular (anáfase) em conseqüência de um evento clastogênico (quebra cromossômica) ou aneugênico (segregação cromossômica anormal). São biomarcas expressas nas células filhas em decorrência de danos induzidos às células mães (Ribeiro, 2003). De acordo com Çavas \& Ergene-Gözükara (2003), alterações morfológicas nucleares são consideradas biomarcas de estresse ambiental; tais alterações morfológicas nucleares são indicadores de citotoxicidade enquanto que micronúcleos de genotoxicidade (Benincá, 2006).

Por não ser uma molécula estática, o DNA de um organismo freqüentemente apresenta suas bases expostas a agentes naturais e artificiais, que provocam modificações químicas e estruturais. Tais alterações do material genético são consideradas mutações quando não resultam de segregação ou recombinação (Cabrioti, 2005). Danos genéticos não reparados geram mutações nos organismos expostos, as quais podem potencialmente resultar em doenças como câncer, anemia, distúrbios cardiovasculares e neurocomportamentais, além de doenças hereditárias (CETESB, 2006).

O objetivo principal deste estudo foi analisar o potencial citogenotóxicos em um recurso hídrico urbano submetido a esgotamento sanitário doméstico, por meio do teste de micronúcleo e alterações nucleares, em Oreochromis niloticus, além de investigar a presença de alterações nucleares específicas nos pontos de proximidade de esgotamento sanitário em relação à área referência.

\section{MATERIAL E MÉTODOS}

A área selecionada para estudo foi o rio Sapato (Lauro de Freitas-BA), sobre o qual não existem registros ecotoxicológicos. A informação disponível no Departamento de Gestão Ambiental (DGA) da prefeitura de Lauro de Freitas é de que não há sistema de saneamento ambiental, sendo que a evacuação dos dejetos domésticos ocorre através de fossas sépticas ou diretamente no rio (Cabanelas \& Moreira, 2007).

O rio Sapato, que se estende por todo o município de Lauro de Freitas, nasce na APA (Área de Proteção Ambiental), lagoas e dunas do Abaeté na divisa dos municípios de Salvador e Lauro de Freitas e deságua junto ao rio Joanes no oceano Atlântico (divisa Lauro de Freitas/Camaçari) (Fig. 1). A quantidade de despejos domésticos (únicas atividades antropogênicas em seu entorno) lançados ao rio vem aumentando consideravelmente desde o começo da especulação imobiliária na região (Vilas do Atlântico - Praia de Ipitanga - Praia do Flamengo), há 20 anos (Cabanelas \& Moreira, 2007). Não há registro de descarte de agrotóxicos ou de resíduos industriais no efluente.

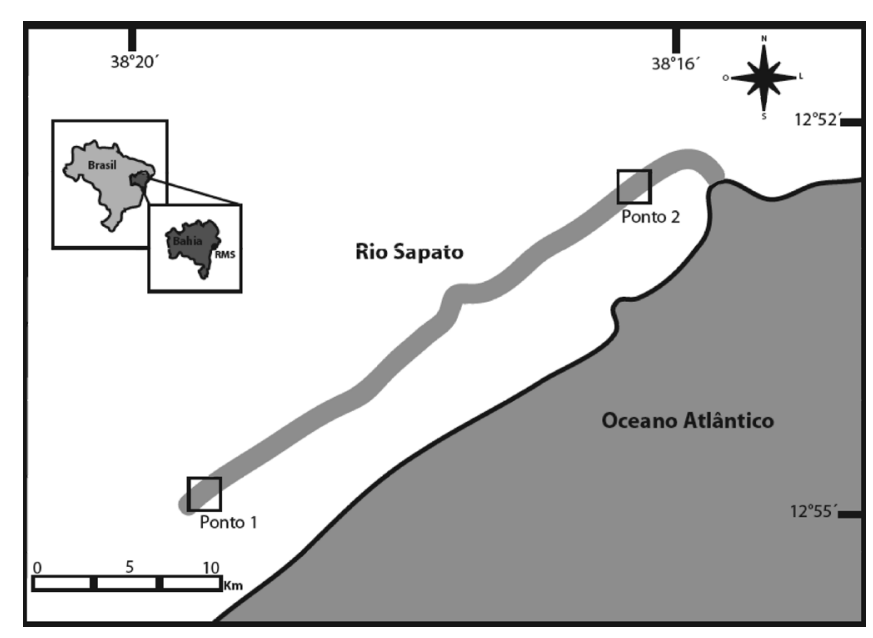

Figura 1 - Mapa do curso do rio Sapato com marcação dos pontos de coleta. Ponto 1 (Referência: Lagoa Vitória); Ponto 2 (Ponto de estudo: rio Sapato).

O biomodelo escolhido foi a tilápia nilótica (Oreochromis niloticus) (Cichlidae, teleostei), espécie exótica, sem registro de sua introdução no rio Sapato, que não possui levantamento ictiofaunístico. Sua escolha para o presente estudo deu-se por 
sua extrema abundância e dieta ampla, além da sensibilidade já demonstrada por outros estudos genotoxicológicos, inclusive no Brasil (Grisolia \& Cordeiro, 2000; Grisolia \& Starling, 2001; Palhares \& Grisolia, 2002; Souza \& Fontanetti, 2006, Grisolia et al., 2009).

O estudo foi realizado em amostras de células coletadas de exemplares de tilápia, tomados de dois pontos de coleta: ponto referência, próximo à nascente (lagoa Vitória, Parque Ecológico e Horto da Restinga, APA Lagoas e Dunas do Abaeté, Salvador -BA - $12^{\circ} 55^{\prime} 01^{\prime \prime}$ S $38^{\circ} 19^{\prime} 08^{\prime \prime} \mathrm{W}-$ ) e ponto rio Sapato, em área submetida a esgotamento sanitário (bairro de Vilas do Atlântico, Lauro de Freitas - BA - 12 $2^{\circ} 3^{\prime} 14^{\prime \prime} \mathrm{S} 38^{\circ} 17^{\prime} 19^{\prime \prime} \mathrm{W}$ - ). As coletas foram realizadas nas estações seca (novembro e dezembro/2006) e chuvosa (março e abril/ 2007).

De cada ponto foram coletados, com rede de pesca, 10 peixes que depois de medidos foram submetidos à punção nas brânquias com seringa de $1,0 \mathrm{~mL}$ heparinizada, seguida de esfregaço em 3 lâminas de microscopia previamente lavadas e identificadas. As lâminas foram secas ao ar por $24 \mathrm{hs}$ e posteriormente fixadas em solução de metanol a $70 \%$ em tampão fosfato $(\mathrm{pH} 6,4)$ por 15 minutos. Após a fixação, as lâminas foram coradas com Giemsa $20 \%$, por 5 minutos, no mesmo tampão. Os peixes foram doados a pescadores locais para consumo, evitando assim a possível repetição de exemplares.

Foram analisadas, de cada exemplar, 3000 células bem evidentes e sem sobreposição (1000 por lâmina, em microscópio óptico com lente de imersão ao aumento total de 1000x). Foram contados os micronúcleos que apresentaram as seguintes características: morfologia idêntica ao núcleo, diâmetro entre $1 / 16$ e $1 / 3$ e coloração igual à do núcleo principal, ausência de refringências, não estavam ligados ou conectados e nem sobrepostos ao núcleo principal (Fenech, 2000).

Foram também registradas outras alterações nucleares foram também registradas e sua classificação seguiu os critérios de Çavas \& Ergene-Gözükara (2003), que discriminam as seguintes anormalidades nucleares:

1) Célula binucleada (BN - célula com dois núcleos dentro de um citoplasma bem evidente e sem sobreposições);

2) Núcleo lobado (LB - com a presença de evaginação);

3) Núcleo bilobado (BL - com uma ou várias evaginações, podendo tornar-se disforme);

4) Núcleo entalhado (NT - que apresenta um corte bem definido em sua forma).

Foram realizadas fotomicrografias de algumas células selecionadas, com auxílio de máquina digital sony e aparelho de adaptação para microcópio Carl Zeiss Axiostar plus . As imagens foram visualizadas através do software iPhoto versão mac2004. Os dados foram tabulados no software microsoft excel versão mac2004 e a análise estatística feita no programa GraphPad InStat versão mac, para realização dos testes de checagem das premissas (Barttlet para checagem das homogeneidade das variâncias e Kolmorogov-Smirnov para checagem da normalidade da distribuição) seguidos pelo teste de Kruskal-Wallis (ANOVA não-paramétrica) com o teste posterior de Dunn.

Os parâmetros físico-químicos foram analisados de acordo com a metodologia da Associação Americana de Saúde Pública (APHA, 1989).

\section{RESULTADOS}

Os resultados da análise de micronúcleos e outras alterações nucleares são apresentados na Tabela 1. A Figura 2 mostra células com as alterações analisadas.

Tabela 1 - Valores médios ( \pm desvio padrão) de micronúcleos $(\mathrm{MN})$ e outras alterações nucleares* em exemplares de $O$. niloticus nas estações seca e chuvosa.

\begin{tabular}{lcccc}
\hline & \multicolumn{2}{c}{ Ponto 1 } & \multicolumn{2}{c}{ Ponto 2 } \\
\hline & Seca & Chuva & Seca & Chuva \\
MN & $36,2 \pm 8,0$ & $33,2 \pm 13,1$ & $139,6 \pm 32,4$ & $367,2 \pm 66,4$ \\
BL & $18,0 \pm 4,5$ & $16,9 \pm 6,5$ & $46,9 \pm 18,4$ & $48,3 \pm 37,2$ \\
LB & $8,4 \pm 3,9$ & $6,7 \pm 6,7$ & $20,4 \pm 11,5$ & $106,7 \pm 32,7$ \\
NT & $3,8 \pm 2,4$ & $3,7 \pm 1,1$ & $10,8 \pm 6,3$ & $13,7 \pm 13,2$ \\
BN & $02 \pm 0,4$ & $0,4 \pm 0,5$ & $0,9 \pm 0,9$ & $4,8 \pm 3,0$ \\
n & 10 & 10 & 10 & 10 \\
\hline
\end{tabular}

* BL:célula binucleada; LB:núcleo lobado; BL: núcleo bilobado; NT:núcleo entalhado;BN: Celula binucleada ; n: número de amostras.

O teste de Kruskal-Wallis (ANOVA não-paramétrica) calculou um valor de $p<0,0001$, considerado significante, o que indicou que há diferença significativa entre as médias das alterações observadas nos dois pontos. Para a especificação das diferenças entre os grupos, foi aplicado o teste posterior (post-hoc) de Dunn para comparações múltiplas. A análise estatística evidenciou que:

No ponto 1 (Lagoa Vitória) não houve diferença significativa entre as médias de micronúcleos e alterações nucleares, em ambos os períodos (Fig. 3)

No ponto 2 (rio Sapato) houve diferença extremamente significativa para o valor de micronúcleos encontrado na estação chuvosa em comparação aos valores de $\mathrm{MN}, \mathrm{BN}, \mathrm{BL}$, LB e NT na estação seca (Fig. 3)

No ponto 2 houve diferença significativa para o valor de núcleos lobados (LB) na estação chuvosa em comparação à seca; contudo as outras alterações nucleares não mostraram diferenças significativas entre as estações de coleta.

Na tabela 2 estão apresentados os valores para os parâmetros físico-químicos associados com a qualidade ambiental em ecossistemas dulciaquícolas.

\section{DISCUSSÃO}

É importante buscar informações sobre as dimensões dos danos genotóxicos ocasionados pela atividade antropogênica, 

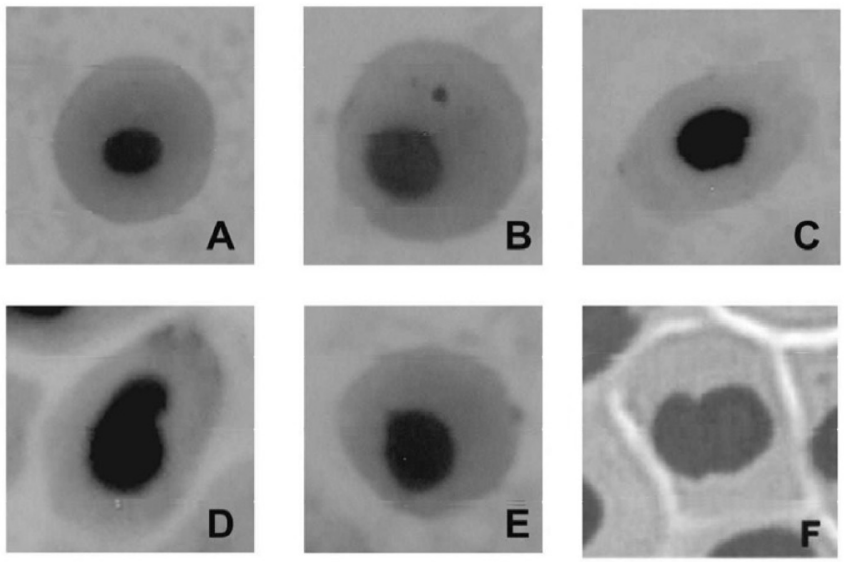

Figura 2 - Fotomicrografias de eritrócitos de $O$. niloticus: células normal (A), micronucleada (B), núcleos bilobado (C), entalhado (D), lobado (E) e célula binucleada $(\mathrm{F})$

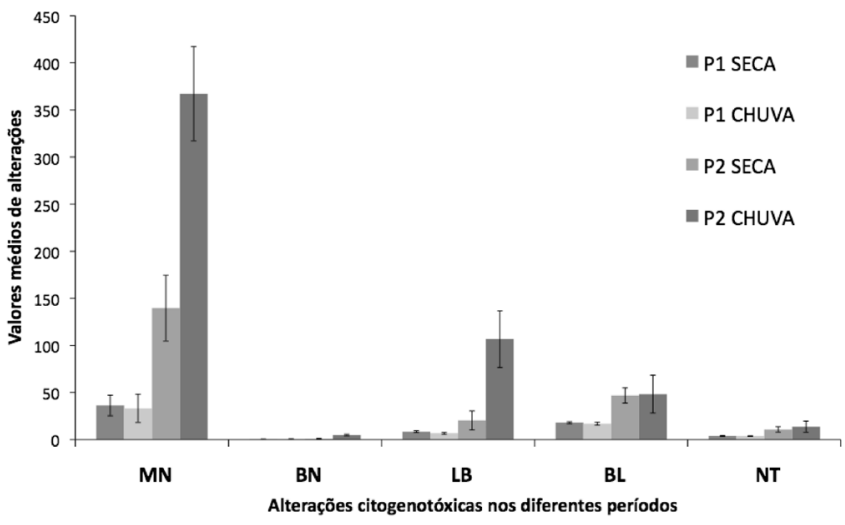

Figura 3 - Valores médios e desvios padrões de micronúcleos e alterações nucleares em exemplares de $O$. niloticus provenientes da Lagoa Vitória (P1) e do rio Sapato (P2) nas estações seca e chuvosa.

Tabela 2 - Parâmetros físico-químicos das amostras de água.

\begin{tabular}{lcccccc}
\hline & OD & Nitrito & Nitrato & Fosfato & $\mathrm{pH}$ & Temperatura \\
\hline $\begin{array}{l}\text { Ponto } \\
1\end{array}$ & 5,13 & 0,013 & 0,1 & 0,076 & 4,7 & 30 \\
$\begin{array}{l}\text { Ponto } \\
2\end{array}$ & 1,71 & 1,92 & 4,96 & 1,72 & 7,1 & 31,5 \\
\hline
\end{tabular}

* OD (Oxigênio Dissolvido) $=\mathrm{mgO}_{2} \mathrm{~L}^{-1} ; \mathrm{NITRITO}=\mathrm{mgNO}_{2} \mathrm{~L}^{-1}$; $\mathrm{NITRATO}=\mathrm{mgNO}_{3} \mathrm{~L}^{-1} ;$ FOSFATO $=\mathrm{mgPO}_{4} \mathrm{~L}^{-1} ;$ TEMPERATURA $=$ graus Celsius.

porque danos genéticos passíveis de acúmulo podem conduzir ao surgimento de lesões não reparáveis, que por sua vez estão ligadas a uma série de patologias, especialmente neoplasias (CETESB, 2006).

As freqüências de micronúcleos e alterações nucleares, observadas no sitio referência (lagoa Vitória), foram baixas quando comparadas ao verificado no ponto de estudo, o que pode ser justificado pela caracterização da área, dentro do Parque Ecológico e Horto da Restinga (propriedade particular e área de proteção ambiental livre de emissões poluidoras) e pela análise química da água (Tabela 2). O mesmo aplica-se à diferença não significativa entre os valores encontrados nas estações seca e chuvosa, no sitio referência.
A análise dos resultados obtidos permitiu verificar que as alterações nucleares $\mathrm{MN}$ e LB responderam como bons biomarcadores para atividade mutagênica. As alterações $\mathrm{BN}, \mathrm{BL}$ e NT entretanto, não se mostraram conclusivas, o que pode ter sido ocasionado pela baixa sensibilidade destas biomarcas, frente as amostras investigadas. Ressaltase também a necessidade de validação destas biomarcas. Contudo, ressalta-se também a necessidade de validação destas biomarcas em estudos in situ, uma vez que são recomendados em estudos de genotoxicidade em geral (Benincá, 2006; Rodriguez-cea et al., 2003; Çavas \& Ergene-gozuka, 2003; Galindo \& Moreira, 2009).

Sabe-se que as alterações nucleares são biomarcas de atividade citotóxica, enquanto que os micronúcleos são biomarcas de atividade genotóxica (Benincá, 2006). Desta forma é correto afirmar que no rio Sapato foram detectadas, pelas freqüências elevadas de micronúcleos e de núcleos lobados (LB), atividade genotóxica e citotóxica, respectivamente.

Benincá (2006) refere-se às AN como biomarcas de citotoxicidade, entretanto pela sua falta de especificidade, ainda não há informações na literatura científica que explicite a qual (ais) mecanismo(s) as AN respondem. Autores como Rodriguez-Cea (2003) atestam a validade do teste do micronúcleo para pesquisas in situ, observando, porém que as condições descontroladas do campo podem levar a resultados inesperados. A falta de controle leva a uma variabilidade de dados muito alta, que acaba por impedir a aplicação de testes estatísticos mais robustos (testes paramétricos), que possuem mais chance de encontrar efeito quando realmente existe. Por este motivo optou-se por substituir controles laboratoriais por um sítio referencia, ferramenta utilizada por vários autores e que permite uma avaliação em conjunto de dados (Rodriguez-cea et al., 2003; Çavas \& Ergenegozuka, 2003; Galindo \& Moreira, 2009).

Com base nos resultados obtidos conclui-se que a avaliação citogenotóxica de um efluente urbano sujeito a esgotamento sanitário contribui para suprir a ausência de estudos não apenas sobre a área em questão, mas também para a validade do teste de micronúcleos e alterações nucleares em estudos de campo, relativamente mais recentes na literatura especializada.

\section{AGRADECIMENTOS}

Os autores agradecem à Vereadora Glória Silva (Lauro de Freitas-BA), bióloga Josane Calina (DGA- Lauro de Freitas), Jorge Santana (UNIDUNAS), Sormani Ferraz (AMIL Lagoas) pelo auxílio com informações técnicas a cerca da área de estudo; ao Sr. Jairo Júnior, Sra. Ana Carolina Almeida, Sr. Carlos Pinheiro e pescadores do rio Sapato, ao Sr. Fernando Pires e Sra. Jorgelina Silva, pelo apoio técnico prestado para execução das análises; e à Profa. Dra. Solange Andrade Pereira (IB/UFBA), pelo auxílio com as análises estatísticas e revisão do texto.

\section{REFERÊNCIAS}

American Public Health Association (APHA), 1989, Standard Methods for the examination of water and wastewater, 17th ed. Washington (DC). 
BENINCÁ, C., 2006, Biomonitoramento das lagoas estuarinas do Camacho - Jaguaruna (SC) e Santa Marta - Laguna (SC); utilizando Geophagus brasiliensis (Cichlidae). Dissertação de Mestrado, Curitiba: UFPR (Universidade Federal do Paraná), PR.

CABANELAS, I.T.D. \& MOREIRA, L. M. A., 2007, Estudo sobre o estado de preservação das nascentes do rio Sapato, Lauro de Freitas-BA. Rev. Cien. Med. Biol. 6 (2): 160-165.

CABRIOTI, L. N., 2005, Estudo da antigenotoxicidade, genotoxicidade e citotoxicidade de frações do extrato metanólico em Agaricus brazei in vitro. Dissertação de Mestrado. Londrina: UEL (Universidade Estadual de Londrina),PR.

CARVAlHO, H. A., 2005, A Tradescantia como bioindicador vegetal na monitoração dos efeitos clastogênicos das radiações ionizantes. Radiol. Bras., 38: 459-462.

ÇAVAS, T. \& ERGENE-GÖZÜKA, S., 2003, Micronuclei, nuclear lesions and interphase silver-stained nucleolar organized regions (AgNORs) as cyto-genotoxity indicators in Oreochromis niloticus exposed to textile mill effluent. Mutat Res., 534: 93-99. (doi:10.1016/S1383-5718(03)00091-3)

CETESB - Companhia de Tecnologia de Saneamento Ambiental. Disponível em: < www.cetesb.org.br $>$. Acesso em: $<12-04-$ 2006>.

FENECH, M., 2000, The in vitro micronucleus technique. Mutat Res., 455: 81-95. (doi:10.1016/S0027-5107(00)00065-8).

GALINDO, T. P. S. \& MOREIRA, L.M.A., 2009. Evaluation of genotoxicity using the micronucleus assay and nuclear abnormalities in the in the tropical sea fish Bathygobius soporator (Valenciennes, 1837) (Teleostei, Gobiidae). Gen. Mol. Bio, 32(2): 394-398. (doi: 10.1590/S1415-47572009000200029).

GRISOLIA, C.K. \& CORDEIRO, C.M.T., 2000, Variability in micronucleus induction with different mutagens applied to several species of fish. Gen. Mol. Bio, 23: 235-239. (doi: 10.1590/ S1415-47572000000100041).

GRISOLIA, C.K. \& STARLING, F.L.R.M., 2001, Micronuclei monitoring of fishes from Lake Paranoá, under influence of sewage treatment plant discharges. Mutat. Res., 491: 39-44. (doi:10.1016/S1383-5718(00)00168-6).
GRISOLIA, C.K., RIVERO, C.L.G., STARLING, F.L.R.M., SILVA, I.,C.,R., BARBOSA, A.C. \& DOREA, J.G., 2009, Profile of micronucleus frequencies and DNA damage in different species of fish in a eutrophic tropical lake. Gen. Mol. Bio, 32: 138-143. (doi: 10.1590/S1415-47572009005000009).

MATSUMOTO, S. T., MANTOVANI, M. S., MALAGUTTII, M. I. A., DIAS, A. L., FONSECA, I. C.; \& MARIN-MORALES, M. A., 2006, Genotoxicity and mutagenicity of water contamined with tannery effluents, as evaluated by the micronucleus test and comet assay using the fish Oreochromis niloticus and chromosome aberrations in onion root-tips. Gen. Mol. Bio, 29: 48-158. (doi: 10.1590/S1415-47572006000100028).

PALHARES, D. \& GRISOLIA, C.K., 2002, Comparison between the micronucleus frequencies of kidney and Gill erythrocytes in tilapia fish, following mitomycin C treatment. Gen. Mol. Bio, 25: 281-284. (doi: 10.1590/S1415-47572002000300005).

RIBEIRO, L. R., 2003, Teste do micronúcleo em medula óssea de roedores in vivo, pp. 173-200. In: RIBEIRO, L. R.; SALVADORI, D. M. F.; MARQUES, E. K. (Orgs.), Mutagênese Ambiental, 355 p., Ed. ULBRA, Canoas.

RODRIGUES, FAC; WEBER, OLS; DORES, EFGC; KLAUTAUGUIMARÃES, MN; TIDON, R \& GRISÓLIA, CK., 2005, Ecogenotoxicologia dos agrotóxicos: avaliação comparativa entre ecossistema agrícola e área de proteção ambiental. Rev. Ecotoxicol. e Meio Amb., 15: 73-84.

RODRIGUEZ-CEA, A.; AYLLON, F.; \& GARCIA-VAZQUEZ, E., 2003, Micronucleus test in freshwater fish species: an evaluation of its sensitivity for application in field surveys. Ecotox. Environ. Saf, 56: 442-448.(doi:10.1016/S0147-6513(03)00073-3).

SOUZA, T.S. \& FONTANELLI, C.S., 2006, Micronucleus test and observations of nuclear alterations in erythrocytes of Nile tilápia exposed to waters affected by refinery effluent. Gen Toxicol Environ Mutagen., 605: 87-93. (doi:10.1016/j. mrgentox.2006.02.010)

VENIER, P; MARON, S; \& CANOVA, S., 1997, Detection of micronuclei in gill cells and haemocytes of mussels exposed to benzo [a] pyrene. Mutat Res., 390: 33-44. (doi:10.1016/S01651218(96)00162-0). 